\title{
Effects of uncertain lifetime and annuity insurance on capital accumulation and growth.*
}

\author{
Luisa Fuster ${ }^{\dagger}$
}

January 1998

\footnotetext{
*I am indebted to Jordi Caballé for his advice and encouragement. I am also very grateful to Andrés Erosa, Angel de la Fuente, and Timothy Kehoe for their useful suggestions and comments. I thank the Department of Economics of the University of Minnesota and the Department of Economics of the University of Western Ontario for their kind hospitality while I was working on the revisions of this paper. Financial support of the Instituto de Estudios Fiscales and the Ministerio de Educación y Ciencia (grant FU94-21471056 and PB94-1095) of Spain is also acknowledged.

†Departament d'Economia i Empresa, Universitat Pompeu Fabra, Ramon Trias Fargas 25-27, 08005-Barcelona. (e-mail: luisa.fuster@econ.upf.es)
} 
Summary. This paper studies the effects of uncertain lifetime on capital accumulation and growth and also the sensitivity of those effects to the existence of a perfect annuities market. The model is an overlapping generations model with uncertain lifetimes. The technology is convex and such that the marginal product of capital is bounded away from zero. A contribution of this paper is to show that the existence of accidental bequests may lead the economy to an equilibrium that exhibits asymptotic growth, which is impossible in an economy with a perfect annuities market or with certain lifetimes. This paper also shows that if individuals face a positive probability of surviving in every period, they may be willing to save at any age. This effect of uncertain lifetime on savings may also lead the economy to an equilibrium exhibiting asymptotic growth even if there exists a perfect annuities market.

Keywords and Phrases: Asymptotic growth, convex technology, uncertain lifetimes, accidental bequests, perfect annuities market.

JEL Classification Numbers: E21, D81, D91. 


\section{Introduction}

It is well known that in the class of convex technology models equilibrium growth is not possible when lifetimes are bounded. This paper studies equilibrium growth in this class of models with bounded but uncertain lifetimes. I show that equilibrium growth is possible when there is no annuities market. I also show that equilibrium growth is possible even in the presence of an annuities market if individuals face a constant conditional probability of surviving at any age.

In an overlapping generations model with a convex technology, Boldrin [3] and Jones and Manuelli [10] demonstrated that equilibrium growth is not possible when lifetimes are deterministic and finite. They also showed that equilibrium growth requires that the young buy from the old an ever increasing stock of capital. But the young cannot afford to buy an increasing stock of capital because their income grows at a lower rate than capital. This suggests two ways of restoring equilibrium growth. One is to provide the young with enough resources to afford an ever increasing stock of capital. I show that accidental bequests can play this role. Another way is to prevent the old from exhausting their assets. I show that if individuals face a positive probability of surviving at any age they may be willing to save at any age.

The effects of uncertain lifetimes on growth have not yet been analyzed. The early contributions in the literature focused on the effects of uncertain lifetimes on individuals' savings decisions in a partial equilibrium setting (see, for instance, Yaari [13] and Davies [4]). More recently Abel [1] and also Kotlikoff, Shoven, and Spivak [11] focused on the impact of uncertain lifetimes and annuity insurance on aggregate wealth accumulation. Abel used a partial equilibrium model for an analytical study while Kotlikoff et al. relied on simulations using a general equilibrium setting. In contrast to these analyses my paper provides an analytical study of the growth effects of uncertain lifetimes in a general equilibrium framework.

I use a version of the standard overlapping generations model used by Boldrin [3] and Jones and Manuelli [10] where lifetimes are uncertain. In particular, I develop two models of uncertain lifetime: bounded uncertain lifetime and unbounded un- 
certain lifetime. In the first model individuals' age has a bounded support while in the second the support of individuals' age is unbounded. In both models expected lifetime is finite.

I use the first model to show that equilibrium growth is possible in the class of convex technology models with finite horizons. If there is no annuities market, there is a region of parameter values for which there exists an equilibrium that exhibits growth and that is unique. On the other hand, if there are annuities, growth is not possible because annuities preclude accidental bequests.

My model with bounded lifetimes can be viewed as a general equilibrium version of the framework studied in Abel [1]. Abel found that an annuities market may induce an increase or a decrease in aggregate capital accumulation depending on the elasticity of intertemporal substitution of consumption. My findings show that Abel's results only apply when the equilibrium of the economy without annuity insurance does not exhibit growth.

In the model with unbounded uncertain lifetimes, equilibrium growth is possible even when there are no accidental bequests. Transfers to the young are not necessary for growth because there is no generation willing to exhaust their assets. In fact growth is possible at equilibrium because individuals choose a strictly increasing asset holdings path. This decision is optimal if the interest rate is sufficiently high. In particular, if the interest rate is higher than the intertemporal discount rate, the possibility of surviving induces individuals to save at any age.

The findings in the unbounded uncertain lifetime model lead us to conclude that the length of the support of individuals' age is crucial for asymptotic growth. The importance of the length of lifetime for savings has been studied before in models with uncertain lifetime. Davies [4] found that the larger the support of the distribution of individuals' age is, the more individuals save out of their wealth. Davies did not explore the consequences of his finding for capital accumulation. My paper demonstrates that Davies's finding is in fact very important for the existence of equilibrium growth in the class of convex technology models. 
The remainder of this paper is organized as follows. Section 2 describes the model economy. Section 3 shows that in a life-cycle convex technology model with accidental bequests, long-run growth is possible. Section 4 shows that long-run growth is possible even if there are no accidental bequests when individuals assign a positive probability to the state of surviving.

\section{The model}

The model economy is a one sector overlapping generations model with uncertain lifetimes. In every period, a new generation of measure one of individuals is born. At the end of a period, individuals face a positive probability of dying $p \in(0,1)$. This probability is common knowledge and does not differ across ages. Under these assumptions, an individual's age has a support $(1, T]$. I will consider two models of uncertain lifetime: bounded uncertain lifetime and unbounded uncertain lifetime. In the first model, individuals' age has a bounded support $(1, T]$, where $T<\infty$. In the second model, individuals' age has an unbounded support, that is, $T \rightarrow \infty$.

There is a single good that can be either consumed or used as input in the production process. The technology is convex and uses capital and labor as inputs. Because the production function exhibits constant returns to scale in capital and labor, output per worker is a function of capital per worker, $y_{t}=f\left(k_{t}\right)$. This function is twice continuously differentiable and satisfies that $f(0)=0, f(k)>0$, $f^{\prime}(k)>0, f^{\prime \prime}(k)<0$, for all $k>0$. It also satisfies the Inada condition at the

origin, that is, $\lim _{k \rightarrow 0} f^{\prime}(k)=\infty$, which is a sufficient condition for the existence of a non trivial equilibrium path. Another property of this technology is that output is unbounded since there is not a maximum sustainable capital stock. As in Gale and Sutherland [9] and Jones and Manuelli [10], the marginal product of capital is always positive. In particular the marginal product of capital satisfies the following condition for high levels of capital:

$$
\lim _{k \rightarrow \infty} f^{\prime}(k)=\rho>\delta
$$


where $\delta \in[0,1]$ is the constant rate of depreciation of capital. An additional assumption, taken from Galor and Ryder [8] and Boldrin [3], is that the ratio of wage to capital, $\omega / k=f(k) / k-f^{\prime}(k)$, is decreasing with respect to capital. This condition is crucial to the existence of a steady state equilibrium in a standard overlapping generations model. An example of the technology that I have just described is the production function $f(k)=g(k)+\rho k$, where $\lim _{k \rightarrow \infty} g^{\prime}(k)=0$ (see, Jones and Manuelli $[10])$.

Input markets are competitive. The representative firm maximizes its profits taking prices as given. In equilibrium, firms make zero profits and inputs are paid at their marginal products,

$$
\begin{gathered}
R_{t}=1+f^{\prime}\left(k_{t}\right)-\delta \\
\omega_{t}=f\left(k_{t}\right)-k_{t} f^{\prime}\left(k_{t}\right),
\end{gathered}
$$

where $R_{t}$ is the interest rate and $\omega_{t}$ is the wage. From equations (2.1) and (2.2),

$$
\lim _{k \rightarrow \infty} R(k)=1+\rho-\delta>1 .
$$

I define $\pi=1+\rho-\delta$ for simplicity of notation.

\section{Bounded uncertain lifetime and growth}

This section focuses on the effects of uncertain lifetimes on capital accumulation, growth, and wealth distribution. It also analyzes the sensitivity of these effects to the existence of a perfect annuities market. The model is a general equilibrium version of the model in Abel [1]. The main contribution of this section is to show that in a finite lifetime model with a convex technology, long-run growth becomes possible when the young receive accidental bequests.

For simplicity, I assume that individuals live at most two periods $(T=2)$, their preferences are additively separable in the consumption at both periods, and the utility function is isoelastic. When young individuals are endowed with one unit of labor that they supply to firms in exchange for a wage payment. When old, they are retired and receive the return of their savings. Since lifetimes are uncertain 
and there is not an annuities market, young risk averse individuals save capital to consume if they survive. If an individual dies early, the return of his savings is passed on to his children and constitutes an accidental bequest.

The decision problem of an individual born in period $t$ is to choose the pair of consumptions that maximizes his lifetime expected utility, subject to two budget constraints,

$$
\begin{aligned}
\underset{\left\{c_{t}(t), c_{t+1}(t)\right\}}{\operatorname{Max}}\left\{u\left(c_{t}(t)\right)+(1-p) \beta u\left(c_{t+1}(t)\right)\right\} \\
\text { s.to }: \quad c_{t}(t)+s_{t} \leq \omega_{t}+b_{t} \\
c_{t+1}(t) \leq R_{t} s_{t} \\
s_{t} \geq 0
\end{aligned}
$$

where $u(c)=c^{1-\sigma} /(1-\sigma)$, for $\sigma>0, \sigma \neq 1$ and $u(c)=\log (c)$ for $\sigma=1$. The parameter $\sigma$ is the inverse of the elasticity of intertemporal substitution of consumption, and $\beta$ is the intertemporal discount factor. In a given period $i, c_{i}(t)$ is the consumption of an individual born in $t, s_{i}$ are the asset holdings of a young individual, and $b_{i}$ is the accidental bequest received by a young individual. Asset holdings are constrained to be non-negative because individuals cannot die in debt. The reason for this is that there are no institutions that allow parents to force their children to give them gifts.

Lifetime uncertainty constitutes a source of heterogeneity in the distribution of wealth. An individual receives a positive bequest if and only if their parents die early. The amount he receives depends on the mortality history and on the asset holdings of his family in the following way:

$$
b_{t+1}=\left\{\begin{array}{l}
0 \quad \text { with probability }(1-p), \\
R_{t+1} s_{t}\left(\omega_{t}+b_{t} ; R_{t+1}\right) \text { with probability } p,
\end{array}\right.
$$

where $s_{t}\left(\omega_{t}+b_{t} ; R_{t+1}\right)$ represents the optimal asset holdings of his parents.

The law of motion of the accidental bequests defines a Markov chain with a transition function $P: \Re_{+} \times \varphi[0, \infty) \rightarrow[0,1]$,

$$
P\left(b_{t}, B\right)=(1-p) X_{B}(0)+p X_{B}\left(R_{t+1} s_{t}\left(\omega_{t}+b_{t} ; R_{t+1}\right)\right),
$$


where $X_{B}(\cdot)$ is such an indicator function that $X_{B}(i)=0$ if $i \neq B$ and $X_{B}(i)=1$ if $i \in B$, and $\varphi[0, \infty)$ is the Borel algebra for $\Re_{+}$. The number $P\left(b_{t}, B\right)$ records the probability that the bequest moves from the state $b_{t}$ to some state in the Borel set $B$ between periods $t$ and $t+1$. Given an initial distribution of bequests $\psi_{0}$, the transition function (3.3) defines a sequence of distributions $\left\{\psi_{t}\right\}_{t=0}^{\infty}, \psi_{t}: \varphi[0, \infty) \rightarrow$ $\Re_{+}$for all $t$.

Definition 1. An equilibrium is a sequence of prices $\left\{\omega_{t}, R_{t}\right\}_{t=0}^{\infty}$, a function of optimal asset holdings $s_{t}\left(\omega_{t}+b_{t} ; R_{t+1}\right)$, a sequence of capital per worker $\left\{k_{t}\right\}_{t=0}^{\infty}$, and a sequence of distribution functions of bequests $\left\{\psi_{t}\right\}_{t=0}^{\infty}$, such that satisfy the following conditions:

i) given prices $\left(\omega_{t}, R_{t}\right)$ and $b_{t}, s_{t}\left(\omega_{t}+b_{t} ; R_{t+1}\right)$ is optimal for an individual born in $t$ who received a bequest $b_{t}$,

ii) factors are paid at their marginal products (Eq. (2.2) and (2.3)),

iii) markets clear, $k_{t+1}=\int s_{t}\left(\omega_{t}+b ; R_{t+1}\right) \psi_{t}(d b)$ and

$f\left(k_{t}\right)+(1-\delta) k_{t}=\int\left(c_{t}\left(t, \omega_{t}+b ; R_{t+1}\right)+s_{t}\left(\omega_{t}+b ; R_{t+1}\right)\right) \psi_{t}(d b)+\int c_{t}\left(t-1, \omega_{t-1}+\right.$ $\left.b ; R_{t}\right) \psi_{t-1}(d b)$,

iv) given $\psi_{0}, \psi_{t+1}(B)=(1-p) X_{B}(0)+p \int_{G} \psi_{t}(d b)$, where $G=\left\{b: R_{t+1} s_{t}\left(\omega_{t}+\right.\right.$ $\left.\left.b ; R_{t+1}\right) \in B\right\}$, for all $B \in \varphi[0, \infty)$.

The third condition means that the capital market and the good market clear, respectively. The capital market clearing condition requires that firms' demand for capital in period $t+1$ must equal aggregate assets holdings in $t$. The fourth condition says that the distribution of bequests evolves in time according to the transition function, Eq. (3.3).

Definition 2. A steady state is an equilibrium where the capital per worker, prices of inputs, and the distribution function of bequests remain invariant.

The last condition implies that there exists a function $\psi^{*}$ that satisfies that

$$
\psi^{*}(B)=(1-p) X_{B}(0)+p \int_{G} \psi^{*}(d b) .
$$

The assumption of homothetic preferences greatly simplifies the computation of 
the equilibrium, since aggregate allocations and prices will only depend on the first moment of the distribution of wealth. Individuals' optimal assets holdings are a fraction of their initial wealth, $\omega_{t}+b_{t}$. This fraction is a time invariant function of the next period interest rate, $g: \Re_{+} \rightarrow[0,1]$,

$$
g\left(R_{t+1}\right)=\frac{1}{1+R_{t+1}^{1-1 / \sigma}[(1-p) \beta]^{-1 / \sigma}} .
$$

Note that $g\left(R_{t+1}\right)$ is constant across individuals with different wealth. Therefore, aggregate assets holdings only depend on the mean of the wealth distribution,

$$
\int s_{t}\left(\omega_{t}+b ; R_{t+1}\right) \psi_{t}(d b)=g\left(R_{t+1}\right)\left[\omega_{t}+\int b \psi_{t}(d b)\right]
$$

The above expression can be rewritten as a first order difference equation on the aggregate assets of the economy by using Eq. (3.2),

$$
\int s_{t}\left(\omega_{t}+b ; R_{t+1}\right) \psi_{t}(d b)=g\left(R_{t+1}\right)\left[\omega_{t}+p R_{t} \int s_{t-1}\left(\omega_{t-1}+b ; R_{t}\right) \psi_{t-1}(d b)\right] .
$$

Since in equilibrium aggregate asset holdings equal next period capital stock and inputs prices equal their marginal products, I obtain from the previous equation that

$$
k_{t+1}=g\left(1+f^{\prime}\left(k_{t+1}\right)-\delta\right)\left[f\left(k_{t}\right)-(1-p) k_{t} f^{\prime}\left(k_{t}\right)+p(1-\delta) k_{t}\right],
$$

where $g\left(1+f^{\prime}\left(k_{t+1}\right)-\delta\right)$ was defined in Eq. (3.5). Then, given an initial distribution of bequests $\psi_{0}$ and an initial capital stock $k_{0}$, an equilibrium is characterized by a sequence of capital stocks $\left\{k_{t}\right\}_{t=0}^{\infty}$ satisfying (3.6). This sequence of capital stocks is growing at a gross rate $\gamma_{t} \equiv k_{t+1} / k_{t}$. The asymptotic growth rate of capital, $\gamma$, is defined as the limit of $\gamma_{t}$ when the capital stock tends to infinite. Dividing both sides of (3.6) by $k_{t}$ and taking limits as $k_{t} \rightarrow \infty$ gives, $\gamma=p \pi g(\pi)$, where $\pi=\lim _{k \rightarrow \infty}\left(1+f^{\prime}(k)-\delta\right)$.

The next proposition shows that there exists a unique equilibrium sequence of capital stocks and that this sequence may be unbounded. This proposition assumes an elasticity of intertemporal substitution greater than unity which guarantees the uniqueness of the equilibrium path. If the elasticity of intertemporal substitution 
is lower than unity, there could also exist an unbounded sequence of capital stocks that may not be unique.

Proposition 1. Assume that $\sigma \leq 1$, then for any $k_{0}$ the Eq. (3.6) has a unique solution which is a sequence of capital stocks $\left\{k_{t}\right\}_{t=0}^{\infty}$. The sequence that characterizes the unique equilibrium path, $\left\{k_{t}\right\}_{t=0}^{\infty}$, is unbounded if and only if $p \pi g(\pi) \geq 1$.

Proof. See the Appendix A.

Proposition 1 shows that if the elasticity of intertemporal substitution is greater than unity, there exists a unique equilibrium path. The unique equilibrium sequence of capital stocks exhibits long-run growth if and only if the asymptotic rate of growth of capital is positive, that is,

$$
\gamma=\frac{p \pi}{1+\pi^{1-1 / \sigma}[(1-p) \beta]^{-1 / \sigma}}>1
$$

For which it is necessary that $p \pi>1$ and $\pi(1-p) \beta>1$.

Asymptotically, the economy grows faster as the limiting return of capital, $\pi$, increases. Moreover, a greater elasticity of intertemporal substitution of consumption, $1 / \sigma$, implies a larger asymptotic rate of growth (since $\pi(1-p) \beta>1$ ). In any case, lifetime uncertainty is a necessary condition to generate sustained growth. In fact, as the probability of dying, $p$, tends to one or to zero, the asymptotic rate of growth, $\gamma$, tends to zero. Figure 1 illustrates the relationship between lifetime uncertainty and growth.

\section{[Insert Figure 1 here.]}

The next two propositions show some properties of the equilibrium distribution of bequests in the economy. The first of them analyzes the distribution of the wealth of the economy in the equilibrium displaying sustainable growth. Since in this equilibrium wages grow at a lower rate than capital, the ratio of wage to capital stock tends to zero for high levels of capital. This means that individuals who do not receive any bequest own an ever decreasing proportion of the wealth of the 
economy. The distribution of wealth of the economy concentrates because there is an ever decreasing proportion of people that owns an ever increasing proportion of the capital stock. The richest families are the ones that are accumulating wealth for the highest number of periods (those with the worst mortality history). Individuals belonging to these families become the owners of the capital stock.

Proposition 2. Assume that $\sigma \leq 1$ and $p \pi g(\pi) \geq 1$. As aggregate capital tends to infinity, the equilibrium distribution of the ratio of bequest to capital degenerates to complete inequality given that an ever decreasing proportion of individuals receive and ever increasing ratio of bequest to capital.

Proof. See Appendix A.

The next proposition shows that at the steady state, there exists a unique invariant distribution of bequests, which support may be unbounded. If the support of the distribution of bequests is boundless we can not apply standard theorems to prove the existence of a unique invariant distribution (for example, Theorem 11.12 in Stokey, Lucas, and Prescott [12]). In this case, I follow Doob [5] to prove the existence and uniqueness of the invariant distribution of bequests.

Proposition 3. Assume that $\sigma \leq 1$ and $p \pi g(\pi)<1$. There exists a unique invariant distribution of bequests at the steady state. The support of this distribution is unbounded if $R g(R) \geq 1$, where $R$ is the steady state interest factor of capital.

Proof. See Appendix A for the proof of the first part of this proposition. The second part follows from the analysis by Abel [1]. Since individuals receive a positive bequest if and only if their parents die early, the bequest received depends on the number of consecutive ancestors who died early. Abel [1] fully characterizes the support of the distribution of bequests at a steady state as

$$
b_{N}=\omega \sum_{i=1}^{N}(R g(R))^{i},
$$

where $N$ denotes the number of the last ancestors that consecutively died early in a family. From the above expression we deduce that this support is unbounded if $R g(R) \geq 1$ although the mean of the distribution is bounded because $p R g(R)<1$. 


\subsection{Effects of annuity insurance on capital accumulation}

Abel [1] analyzed only the partial equilibrium effects of annuity insurance on the aggregate wealth of the economy. He pointed out that the existence of a perfect annuities market induces two partial equilibrium effects on savings. One is a negative wealth effect due to the elimination of accidental bequests. The other effect on savings is due to the fact that with annuities the return on savings increases. This last effect is positive if the elasticity of intertemporal substitution is greater than unity, or it is negative otherwise. As a consequence, the aggregate effect of annuity insurance on wealth accumulation is negative if the elasticity of substitution is lower than unity. Otherwise the sign of the aggregate effect is ambiguous.

The analysis in this section shows that the findings by Abel only apply when the equilibrium of the economy without annuity insurance does not exhibit growth. Abel [1] did not address either whether accidental bequests can generate growth in a convex technology model or how an annuities market affects equilibrium growth. Regarding the first of these questions, Proposition 1 shows that the equilibrium path exhibits sustained growth if $\pi p g(\pi)>1$ and that it is unique if the elasticity of intertemporal substitution is greater than unity. The answer to the second question is that a perfect annuities market precludes equilibrium growth because it eliminates accidental bequests. Without accidental bequests asymptotic growth is not feasible. The reason is that the only source of savings are wages as it happens in the certain lifetime model used by Boldrin [3, Appendix] and Jones and Manuelli [10]. Because in equilibrium wages grow at a lower rate than capital, the economy's rate of growth tends to zero.

The next section shows that even in an economy where there is an annuities market, uncertainty about lifetimes is crucial to growth. The reason is that uncertain lifetimes can induce individuals to accumulate wealth at any age in which case the economy may exhibit equilibrium growth. 


\section{Unbounded uncertain lifetime}

This section considers the unbounded uncertain lifetime model which is a discrete time version of the Perpetual Youth model by Blanchard [2]. The simplicity of the model is also worth it in this section because I am looking for an example of positive equilibrium growth. This economy differs from the initial economy in two assumptions. First, we do not impose an upper bound on an individual's lifetime, though we continue to assume that the expected lifetime is finite. An individual's expected lifetime is the reciprocal of $p$ because every period he faces the same positive probability of dying $p$.

Second, there exists a perfect annuities market. Since the annuities market is perfect, annuities companies offer a fair return $Q_{t+1}$. In each period $t$ annuities companies offer to individuals a contract that guarantees $Q_{t+1}$ units of good if they survive by paying one unit of good today. Companies rent their funds to firms which use these funds as capital input. At the end of each period, annuity companies receive the return of their investment which is redistributed to the survivors. Competition guarantees zero expected profits and, therefore, a fair return to annuities,

$$
Q_{t+1}=R_{t+1} /(1-p)
$$

Annuity companies will not only sell annuities to young individuals, but also buy annuities.

The preferences of any individual born in $t$ are represented by

$$
E_{t} U\left(\left\{c_{t}(t), c_{t+1}(t), c_{t+2}(t), \ldots\right\}\right)=\sum_{i=0}^{\infty}(\beta(1-p))^{i} u\left(c_{t+i}(t)\right),
$$

where the utility function is the same considered in Section 3.

We know from Yaari [13] that the optimal portfolio allocation of selfish individuals is to buy annuities and not to hold capital. As a consequence, there are no accidental bequests and individuals are homogeneous with respect to their initial wealth. Then, in any period $t$ there is a representative newborn individual who chooses the sequences of consumptions $\left\{c_{i}(t)\right\}_{i=t}^{\infty}$ and purchases of annuities 
$\left\{a_{i}(t)\right\}_{i=t}^{\infty}$ that maximize (4.2) subject to the budget constraints,

$$
c_{j}(t)+a_{j}(t)=Q_{j} a_{j-1}(t)+\omega_{j},
$$

under the no debt rollover constrain,

$$
\lim _{T \rightarrow \infty} a_{T}(t)\left(\prod_{i=j+1}^{T} Q_{i}\right)^{-1}=0,
$$

where $j=t-1, t, \ldots$ and $a_{t-1}(t)=0$.

Definition 3. An equilibrium is a sequence of prices $\left\{\omega_{t}, R_{t}, Q_{t}\right\}_{t=0}^{\infty}$, allocations

$\left\{\left\{c_{j+i}(j), a_{j+i}(j)\right\}_{i=0}^{\infty}\right\}_{j=0}^{\infty}$, and a sequence of capital per worker $\left\{k_{t}\right\}_{t=0}^{\infty}$ such that satisfy the following conditions:

i) Given prices, $\left\{c_{j+i}(j), a_{j+i}(j)\right\}_{i=0}^{\infty}$ solves the maximization problem of an individual born in period $j$,

ii) factors prices satisfy the profit maximization conditions (2.2) and (2.3), and

iii) the return of annuities is fair, $Q_{t}=R_{t} /(1-p)$,

ii) markets clear, that is, the capital market satisfies the condition $k_{t+1}=\sum_{i=0}^{\infty} \frac{(1-p)^{i}}{N} a_{t}(t-$

$i)$, and the good market satisfies the condition $f\left(k_{t}\right)+(1-\delta) k_{t}=\sum_{i=0}^{\infty} \frac{(1-p)^{i}}{N}\left(c_{t}(t-i)+a_{t}(t-i)\right)$.

Aggregate purchase of annuities is defined as $A_{t}=\sum_{i=0}^{\infty}(1-p)^{i} a_{t}(t-i)$. The capital market clears when aggregate purchase of annuities is equal to the next period aggregate stock of capital, $k_{t+1}=A_{t} / N$, where $N$ represents the working population, $N=\sum_{i=0}^{\infty}(1-p)^{i}=1 / p$.

This analysis focuses on the behavior of the economy when capital per worker is sufficiently high so that the interest rate is close to its asymptotic value. For this reason, from now on I will denote the interest factor by $\pi$.

An optimal sequence of consumption of an individual born in $t$ must satisfy the Euler equation and the transversality condition or Eq. (4.4). The Euler equation implies that an individual's consumption grows at a gross rate $(\beta \pi)^{1 / \sigma}$, that is,

$$
(\beta \pi)^{1 / \sigma} c_{j}(t)=c_{j+1}(t)
$$


From this equation we deduce that a newborn individual would save a positive amount if and only if $\beta \pi>1$. This is because his initial wealth is zero and the wage profile is increasing. In that case, an increasing lifetime consumption path would be optimal, which is a necessary condition for equilibrium growth. On the other hand, the transversality condition implies that the rate of growth of individuals' consumption must to be lower than the asymptotic interest rate of annuities,

$$
(\beta \pi)^{1 / \sigma}<\pi /(1-p)
$$

This condition imposes a bound on the limiting marginal product of capital, which is necessary for there to be an equilibrium interest rate. Then the above two inequalities are necessary conditions for the existence of equilibrium growth. In order to find sufficient conditions, we have to study the aggregate behavior of the economy.

Appendix B shows that, in equilibrium, aggregate consumption, aggregate purchase of annuities, and factor prices satisfy the following equations:

$$
\begin{gathered}
C_{j}=\left[1-(1-p)\left(\beta \pi^{1-\sigma}\right)^{1 / \sigma}\right]\left\{\frac{1}{p} Z_{j}+\pi A_{j-1}\right\}, \\
\left(Z_{j}-\omega_{j}\right) \frac{\pi}{1-p}=Z_{j+1}, \\
A_{j}=\frac{1}{p} \omega_{j}+\pi A_{j-1}-C_{j},
\end{gathered}
$$

where $Z_{j} \equiv \sum_{i=j}^{\infty} \frac{\omega_{i}}{(\pi /(1-p)]^{2-3}}$ denotes the human wealth in $j$, and $C_{j}$ is the aggregate consumption. This appendix also shows that the above equations and the capital market clearing condition imply that

$$
\gamma^{2}-\left\{\frac{\pi}{1-p}+(1-p)(\beta \pi)^{1 / \sigma}\right\} \gamma+(\beta \pi)^{1 / \sigma} \pi=0
$$

where $\gamma$ is the asymptotic gross rate of growth of capital per worker, that is, $\gamma \equiv \lim _{k_{j} \rightarrow \infty}$ $\frac{k_{j+1}}{k_{j}}$ for all $j$.

Two possible rates of growth of capital are obtained solving (4.5), which are $\gamma_{1}=\pi /(1-p)$ and $\gamma_{2}=(1-p)(\beta \pi)^{1 / \sigma}$. The next lemma rules out the first of them because the sequence of capital that generates is inconsistent with the transversality condition. 
Lemma 1. A sequence of capital per worker that grows at a gross rate $\gamma_{1}=$ $\pi /(1-p)$ cannot be an equilibrium path.

Proof. Assume that a sequence of capital stocks $\left\{k_{t}\right\}_{t=0}^{\infty}$ such that $k_{t+1} / k_{t}=$ $\gamma_{1}$ characterizes an equilibrium path. The transversality condition or Eq. (4.4) implies that, in any period $t$, the aggregate purchase of annuities satisfies that $\lim _{T \rightarrow \infty} p A_{T}[\pi /(1-p)]^{t-T}=0$. Using the capital market equilibrium condition and substituting in the above equation gives, $\lim _{T \rightarrow \infty}\left(\gamma_{1}\right)^{T+1} k_{0}[\pi /(1-p)]^{t-T}=\lim _{T \rightarrow \infty}$ $[\pi /(1-p)]^{t+1} k_{0}>0$, which is a contradiction with the initial assumption. Therefore, a sequence of capital per worker that grows at a gross rate equal to $\gamma_{1}$ cannot be an equilibrium path.

Proposition 4. Consider an economy satisfying $(1-p)(\beta \pi)^{1 / \sigma} \in(1, \pi)$. Under this condition, a sequence of capital per worker $\left\{k_{t}\right\}_{t=0}^{\infty}$ that grows at a gross rate equal to

$(1-p)(\beta \pi)^{1 / \sigma}$ is an equilibrium path such that $\lim _{T \rightarrow \infty} k_{T}=\infty$. In this equilibrium path, aggregate consumption and output also grow at a rate $(1-p)(\beta \pi)^{1 / \sigma}$.

Proof. The inequality $(1-p)(\beta \pi)^{1 / \sigma}<\pi$ guarantees that the sequence of consumption satisfying the Euler equation is optimal. The sequence of capital growing at a gross rate

$(1-p)(\beta \pi)^{1 / \sigma}$ is an equilibrium path because it satisfies Eq. (4.5). The inequality $(1-p)(\beta \pi)^{1 / \sigma}>1$ guarantees that this equilibrium path exhibits sustained growth.

In this economy there exists an equilibrium path that exhibits asymptotic growth if the conditions of Proposition 4 are satisfied. At this equilibrium, capital per worker and output per worker grow without bound. As capital tends to infinity, the rental price of capital tends to $\pi$ while the rate of growth of wages tends to a positive constant. At the limit, capital and output per worker grow at the same positive rate, $(1-p)(\beta \pi)^{1 / \sigma}-1$. The marked area of Figure 2 shows the pairs of 
values of the coefficient of relative risk aversion and the limiting interest rate that are consistent with positive asymptotic growth.

[Insert Figure 2 here.]

A necessary condition to make asymptotic growth possible is that there is a positive measure of individuals who chooses a strictly positive asset holdings path (see Fuster [6]). This condition is satisfied in this economy since individuals' savings are positive at any age because the probability of surviving is also positive at any age. The demand of annuities by individuals grows at a gross rate $(\beta \pi)^{1 / \sigma}$ as the rental price of capital is close to its asymptotic value. This is key for the existence of equilibrium growth.

On the contrary, in the framework used by Boldrin [3] and Jones and Manuelli [10] every period there is a generation that consumes all its asset holdings. This property of the model makes asymptotic growth impossible. The intuition behind this result is the following. Assume that individuals holding zero assets decide to save part of their income. If at some age $m$ they decide to consume all their asset holdings, after $m$ periods it will be again optimal to consume all their asset holdings. (I am assuming that the wage profile is constant for simplicity.) Therefore, the asset holdings of an individual are bounded above by the wealth that is accumulated during $m$ periods with zero consumption in every period. This upper bound is finite and imposes a bound to the aggregate wealth of the economy precluding the possibility of equilibrium long-run growth. 


\section{Appendix A}

Proof of Proposition 1. The proofs of the first part and of the second part of this proposition are numbered.

1.) Let $\left\{k_{t}\right\}_{t=0}^{\infty}$ be a sequence of capital stocks that satisfies Eq. (3.6) and, therefore, characterizes an equilibrium path. I will show, by means of a contradiction argument, that Eq. (3.6) has a unique solution $k_{t+1}$ for a given $k_{t}$ that belongs to the sequence $\left\{k_{t}\right\}_{t=0}^{\infty}$.

I rewrite Eq. (3.6) as follows:

$$
k_{t+1}\left[g\left(1+f^{\prime}\left(k_{t+1}\right)-\delta\right)\right]^{-1}=f\left(k_{t}\right)-(1-p) k_{t} f^{\prime}\left(k_{t}\right)+p(1-\delta) k_{t},
$$

and define the functions $L\left(k_{t+1}\right)=k_{t+1}\left[g\left(1+f^{\prime}\left(k_{t+1}\right)-\delta\right)\right]^{-1}$ and $D\left(k_{t}\right)=f\left(k_{t}\right)-(1-p) k_{t} f^{\prime}\left(k_{t}\right)+p(1-\delta) k_{t}$. By strictly concavity of the production function, the function $D\left(k_{t}\right)$ is strictly increasing for all $k_{t}>0$. On the other hand, $L^{\prime}\left(k_{t+1}\right)=\left[g(\cdot)-k_{t+1} g^{\prime}(\cdot) f^{\prime \prime}\left(k_{t+1}\right)\right] /[g(\cdot)]^{2}$, and it is positive if $g(\cdot)>$ $k_{t+1} g^{\prime}(\cdot) f^{\prime \prime}\left(k_{t+1}\right)$. It is straightforward to show that $\sigma \leq 1$ is a sufficient condition for $L^{\prime}(\cdot)>0$ because $f^{\prime}(\cdot)>0$ and $k f^{\prime \prime}(k)<0$.

Suppose now that $k_{t+1}^{1}$ and $k_{t+1}^{2}$ are solutions of Eq. (5.1), for a given $k_{t}$, and that

$k_{t+1}^{1}>k_{t+1}^{2}$. Because $L(\cdot)$ is strictly increasing, $L\left(k_{t+1}^{1}\right)>L\left(k_{t+1}^{2}\right)$ and then $D\left(k_{t}\right)>$ $D\left(k_{t}\right)$, which is a contradiction. Therefore, Eq. (5.1) has a unique solution. Because the function $L(\cdot)$ is strictly increasing, the unique solution of equation (5.1) can be described as $k_{t+1}=L^{-1}\left(D\left(k_{t}\right)\right)$. A composition of strictly increasing functions is strictly increasing with respect to $k_{t}$.

2.) The next step of this proof is to show that the unique sequence of capital stocks that solves Eq. (5.1) is unbounded if and only if $p \pi g(\pi) \geq 1$. To do this, I show that there does not exist a steady state capital stock, $k^{*}$ such that $L\left(k^{*}\right)=$ $D\left(k^{*}\right)$, if and only if $p \pi g(\pi) \geq 1$. Substituting $k_{i}=k^{*}$, for $i=t$ and for $i=t+1$ in 
Eq. (5.1) and dividing both sides by $k^{*}$ gives,

$$
\left[g\left(1+f^{\prime}\left(k^{*}\right)-\delta\right)\right]^{-1}=f\left(k^{*}\right) / k^{*}-(1-p) f^{\prime}\left(k^{*}\right)+p(1-\delta) .
$$

The right hand side of Eq. (5.2) is strictly decreasing with respect to capital because $\omega / k$ is strictly decreasing with respect to capital. Moreover, the right hand side of Eq. (5.2) is bounded below by $p \pi$. On the other hand, because $\sigma \leq 1$, the left hand side of Eq. (5.2) is well defined, non-decreasing, and bounded above by $1 / g(\pi)$. Let us assume that there does not exist a $k^{*}$ that solves Eq. (5.2) and show that such assumption implies that $g(\pi) p \pi \geq 1$. If there does not exist a $k^{*}$ it is because the functions defined by the left and by the right hand sides of Eq. (5.2) never cross. This can happen in the case that $p \pi \geq 1 / g(\pi)$. The second part of the proof is trivial since it requires to show that $g(\pi) p \pi \geq 1$ implies that there does not exist any $k^{*}$ that solves Eq. (5.2).

Proof of Proposition 2. In any period $t$, the bequest that an individual receives is characterized by the number of consecutive ancestors who died early (at age 1). I denote by $b_{t, N}$ the bequest received by an individual belonging to a family in which the last $N$ ancestors died early. Then, $b_{t, 0}=0$, and $b_{t, N}=$ $R_{t} g\left(R_{t}\right)\left(\omega_{t-1}+b_{t, N-1}\right)$. Following Abel [1] these bequests are

$$
b_{t, N}=R_{t} g\left(R_{t}\right)\left[\omega_{t-1}+R_{t-1} g\left(R_{t-1}\right) \omega_{t-2}+\ldots+\omega_{t-N} \prod_{i=1}^{N-1} R_{t-i} g\left(R_{t-i}\right)\right] .
$$

Then, the ratio of bequest to the capital stock is

$$
\frac{b_{t, N}}{k_{t}}=R_{t} g\left(R_{t}\right)\left[\frac{\omega_{t-1}}{k_{t}}+R_{t-1} g\left(R_{t-1}\right) \frac{\omega_{t-2}}{k_{t}}+\ldots+\frac{\omega_{t-N}}{k_{t}} \prod_{i=1}^{N-1} R_{t-i} g\left(R_{t-i}\right)\right],
$$

and its limit as $k_{t}$ tends to infinity is

$$
\begin{gathered}
\lim _{k_{t} \rightarrow \infty} \frac{b_{t, N}}{k_{t}}=\left(\lim _{k_{t} \rightarrow \infty} R_{t} g\left(R_{t}\right)\right)\left[\lim _{k_{t} \rightarrow \infty} \frac{\omega_{t-1}}{k_{t}}+\lim _{k_{t} \rightarrow \infty} R_{t-1} g\left(R_{t-1}\right) \frac{\omega_{t-2}}{k_{t}}+\right. \\
\left.+\ldots+\lim _{k_{t} \rightarrow \infty} \frac{\omega_{t-N}}{k_{t}} \prod_{i=1}^{N-1} R_{t-i} g\left(R_{t-i}\right)\right]= \\
=\pi g(\pi)\left[\lim _{k_{t} \rightarrow \infty} \frac{\omega_{t-1}}{k_{t}}+\pi g(\pi) \lim _{k_{t} \rightarrow \infty} \frac{\omega_{t-2}}{k_{t}}+\ldots+(\pi g(\pi))^{N-1} \lim _{k_{t} \rightarrow \infty} \frac{\omega_{t-N}}{k_{t}}\right]=0 .
\end{gathered}
$$


The ratio wage-capital tends to zero as capital tends to infinity (see Eq. (2.3)). Since $N$ is a finite number, the product $(\pi g(\pi))^{N-1}$ is bounded. Therefore, the capital stock is own by individuals receiving the highest bequest. Those individuals belong to families in which the number of ancestors who died early is the highest.

Proof of Proposition 3. I will prove that there exists a unique stationary solution $\psi^{*}$ to the functional equation (3.4). The proof uses the Theorem 5.7 in Doob [5], which shows that the probability measure $\psi^{*}(\cdot)$ exists if the transition function $P$ satisfies Doeblin's condition (see condition D in Doob [5], p. 192) and that it is unique if the state space $S$ has only one ergodic set.

1.) Doeblin Condition: There is a finite measure $\pi$ on $(S, \varphi)$ an integer $N \geq 1$, and a number $\epsilon>0$, such that if $B \in \varphi$ and $\pi(B) \leq \epsilon$, then $P^{N}(b, B) \leq 1-\epsilon$, for all $b \in S$. Proof: Let us suppose, without loss of generality, that $1-p \geq p$. Let $\pi\left(b_{i, N}\right)=p^{i}(1-p)^{N-i}$ for all $b_{i, N} \in S$, where the subindex $i$ indicates the number of ancestors that died at the end of the first period of their lifetime, and $N-i$ is the number of ancestors that were alive in the second period of their lifetime. Therefore, for any $B \in \varphi, \pi(B)=\sum_{b_{i, N} \in B} \pi\left(b_{i, N}\right)$. Let $\epsilon=\min \left(p^{i}(1-p)^{N-i}\right), i=0,1, \ldots, N$. Then, $1-p \geq p$ implies $\epsilon=p^{N}$. Let $B$ be a set such that $\pi(B) \leq \varepsilon \leq p$, then $B$ contains at most one element so that, for all $b, P(b, B) \leq 1-p \leq 1-\varepsilon$, since an accidental bequest is greater than zero.

2.) Since the transition probability function satisfies the Doeblin Condition, there exists at least one ergodic set and at most a finite number of ergodic sets. We have to prove now that there exists a unique ergodic set in $S$ for the transition function $P$. Let us suppose that $E$ and $E^{*}$ are two ergodic sets for the transition function $P$. If I prove that there exists a subset $a \in E \cap E^{*}$ such that $\pi(a)>0$, then $E$ and $E^{*}$ are not distinct ergodic sets. That is, if $P(a, E)=1$ and $P\left(a, E^{*}\right)=1$ then $E$ is equal to $E^{*}$. Since there is a positive probability of surviving, $\pi(0)>0$ and $\inf \{b \in E\}=0$. If $E$ is an ergodic set of $S$, then $P(0, E)=1$ which implies that $0 \in E$. If $E^{*}$ were another ergodic set of $S$, we would get that $0 \in E^{*}$ using the same argument. Thus, $0 \in E \cap E^{*}$. 


\section{Appendix B}

The solution to the maximization problem of an individual born in $t \leq j$ is characterized by

$$
\begin{gathered}
c_{j}=\left[1-(1-p)\left(\beta \pi^{1-\sigma}\right)^{1 / \sigma}\right]\left\{Z_{j}+\frac{\pi}{1-p} a_{j-1}(t)\right\}, \\
a_{j}(t)=\omega_{j}+\frac{\pi}{1-p} a_{j-1}(t)-c_{j}(t),
\end{gathered}
$$

where $Z_{j} \equiv \sum_{i=j}^{\infty} \frac{\omega_{i}}{(\pi /(1-p)]^{i-j}}$ denotes the human wealth in $j$ and where $a_{t-1}(t)=0$. The propensity to consume out of total wealth is age independent. This feature makes aggregation and derivation of close form solutions possible as in Blanchard $[2]$.

Aggregate consumption is defined as $C_{j}=\sum_{i=0}^{\infty}(1-p)^{i} c_{j}(j-i)$. Using this definition, it follows from (6.1) that aggregate consumption is

$$
C_{j}=\left[1-(1-p)\left(\beta \pi^{1-\sigma}\right)^{1 / \sigma}\right]\left\{\frac{1}{p} Z_{j}+\pi A_{j-1}\right\},
$$

and from (6.2) that aggregate investment in annuities is

$$
A_{j}=\frac{1}{p} \omega_{j}+\pi A_{j-1}-C_{j}
$$

The definition of human wealth implies that

$$
\left(Z_{j}-\omega_{j-1}\right) \frac{\pi}{1-p}=Z_{j+1}
$$

Using Eq. (6.3), human wealth is eliminated in (6.5). Thus, Eq. (6.4) is used to eliminate aggregate consumption from Eq. (6.5),

$$
A_{j}=\frac{1}{p} \omega_{j}-\frac{1}{p}(\beta \pi)^{1 / \sigma} \omega_{j-1}+\left\{\frac{\pi}{1-p}+(1-p)(\beta \pi)^{1 / \sigma}\right\} A_{j-1}-(\beta \pi)^{1 / \sigma} \pi A_{j-2} .
$$

Substituting aggregate purchase of annuities by next period aggregate stock of capital in Eq. (6.6), a second order difference equation on capital per worker is obtained. A solution of this equation characterizes an equilibrium path.

Dividing both sides of the difference equation on capital per worker by $k_{j-1}$ and rearranging terms gives

$$
\frac{k_{j+1} k_{j}}{k_{j} k_{j-1}}=\frac{1}{p} \frac{\omega_{j} k_{j}}{k_{j} k_{j-1}}-\frac{1}{p}(\beta \pi)^{1 / \sigma} \frac{\omega_{j-1}}{k_{j-1}}+\left\{\frac{\pi}{1-p}+(1-p)(\beta \pi)^{1 / \sigma}\right\} \frac{k_{j}}{k_{j-1}}-(\beta \pi)^{1 / \sigma} \pi .
$$


Given that I am interested in the asymptotic behavior of the economy, I take limits as $k$ tends to infinity in the previous equation. After rearranging terms, the following equation is obtained:

$$
\gamma^{2}-\left\{\frac{\pi}{1-p}+(1-p)(\beta \pi)^{1 / \sigma}\right\} \gamma+(\beta \pi)^{1 / \sigma} \pi=0
$$

where $\gamma \equiv \lim _{k_{j} \rightarrow \infty} \frac{k_{j+1}}{k_{j}}$ and $\lim _{k_{j} \rightarrow \infty} \frac{\omega_{j}}{k_{j}}=0$.

\section{References}

[1] Abel A. B.: Precautionary saving and accidental bequests. American Economic Review 75, 777-791 (1985).

[2] Blanchard, O. J.: Debt, deficits, and finite horizons. Journal of Political Economy 93, 223-247 (1985).

[3] Boldrin, M.: Dynamic externalities, multiple equilibria, and growth. Journal of Economic Theory 58, 198-218 (1992).

[4] Davies, J.: Uncertain lifetime, consumption, and dissaving in retirement. Journal of Political Economy 89, 561-577 (1981).

[5] Doob, J. L.: Stochastic processes. New York: John Wiley \& Sons Inc. 1953.

[6] Fuster, L.: Growth in convex technology models, manuscript, Universitat Pompeu Fabra, (1996).

[7] Gale, D. and Sutherland, W. R.: Analysis of a one good model of economic development. Mathematics of the Decision Sciences, pt. 2. Providence, R. I.: Dantzig and Veinott editors. American Mathematical Society 1968.

[8] Galor O. and Ryder H. E.: Existence, uniqueness, and stability of equilibrium in an overlapping-generations model with productive capital. Journal of Economic Theory 49, 360-375 (1989). 
[9] Jones L. and Manuelli R.: A convex model of equilibrium growth: theory and policy implications. Journal of Political Economy 98,1008-1038 (1990).

[10] Jones L. and Manuelli R.: Finite lifetimes and growth. Journal of Economic Theory 58 171-197 (1992).

[11] Kotlikoff, L. J., Shoven J., and Spivak, A. : Annuity insurance, savings, and inequality. In: What determines savings? Cambridge, MA: The MIT Press 1989.

[12] Stokey, N. L., Lucas, R. E. with Prescott, E. C.: Recursive Methods in Economic Dynamics. Cambridge, M.A.: Harvard University Press 1989.

[13] Yaari, M. E.: Uncertain lifetime, life insurance, and the theory of the consumer. Review of Economic Studies 32, 137-150 (1965). 
Figure 1: Relationship between the equilibrium rate of growth and lifetime uncertainty.

$$
\pi=10, \quad \beta=0.85, \quad \sigma=0.50
$$


Figure 2: Asymptotic marginal product of capital and elasticity of intertemporal substitution consistent with growth. 